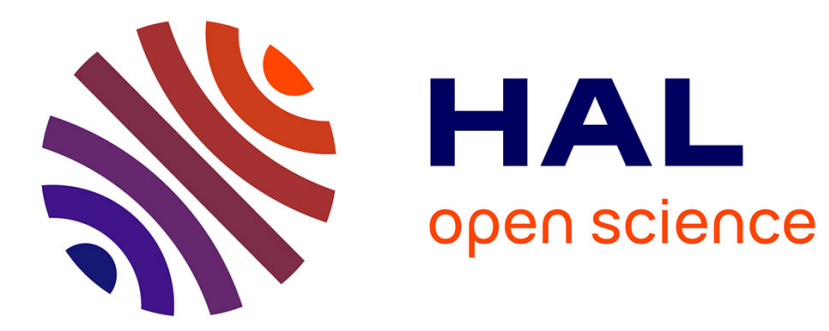

\title{
3D Numerical Simulation of the Var Consumable Electrode Melting Process
}

\author{
Rayan Bhar, A. Jardy, P. Chapelle, Vincent Descotes
}

\section{To cite this version:}

Rayan Bhar, A. Jardy, P. Chapelle, Vincent Descotes. 3D Numerical Simulation of the Var Consumable Electrode Melting Process. Metallurgical and Materials Transactions B, 2020, 51 (6), pp.24922503. 10.1007/s11663-020-01966-x . hal-03093861

\section{HAL Id: hal-03093861 https://hal.science/hal-03093861}

Submitted on 19 Oct 2021

HAL is a multi-disciplinary open access archive for the deposit and dissemination of scientific research documents, whether they are published or not. The documents may come from teaching and research institutions in France or abroad, or from public or private research centers.
L'archive ouverte pluridisciplinaire HAL, est destinée au dépôt et à la diffusion de documents scientifiques de niveau recherche, publiés ou non, émanant des établissements d'enseignement et de recherche français ou étrangers, des laboratoires publics ou privés. 


\title{
3D NUMERICAL SIMULATION OF THE VAR CONSUMABLE ELECTRODE MELTING PROCESS
}

\author{
R. Bhar ${ }^{1,2}$, A. Jardy ${ }^{1}$, P. Chapelle ${ }^{1 *}$ and V. Descotes ${ }^{2}$ \\ ${ }^{1}$ Institut Jean Lamour - UMR CNRS 7198, LabEx DAMAS, Université de Lorraine, 2 allée \\ André Guinier, Campus Artem, 54011 Nancy Cedex, France \\ ${ }^{2}$ Aperam Alloys Imphy - Avenue Jean Jaurès, BP-1, 58160 Imphy, France \\ *e-mail: pierre.chapelle@univ-lorraine.fr
}

Keywords: VAR process, consumable electrode, dripping, liquid metal film, melt rate

\begin{abstract}
A 3D numerical model was set-up to simulate the formation and dynamics of the liquid metal film under the consumable electrode during VAR process. In the present paper the implementation of this model is described. It was developed using the open source computational fluid dynamics (CFD) software OpenFOAM. The model solves coupled momentum and energy equations combined with a volume-of-fluid (VOF) method to track the liquid metal free surface. The melting of the electrode material is modelled with an enthalpyporosity approach. The electric power supplied by the arc is supposed to be uniformly distributed over the surface of the electrode tip. For a given electric arc power, the model enable to quantitatively predict the dripping rate, hence the overall melt rate. Besides the thermal behavior of the electrode, simulation results illustrate the dynamics of the liquid film and the transfer mechanisms of the liquid metal during VAR melts performed with short and long interelectrode gaps.
\end{abstract}

\begin{tabular}{|c|c|c|}
\hline Symbol & Description & Unit \\
\hline $\boldsymbol{\alpha}_{\mathbf{m}}$ & Metal volume fraction & {$[-]$} \\
\hline $\boldsymbol{\beta}$ & Dilatation coefficient & {$\left[\mathrm{K}^{-1}\right]$} \\
\hline$\gamma$ & Solid volume fraction & {$[-]$} \\
\hline$\varepsilon$ & Turbulent kinetic energy dissipation rate & {$\left[\mathrm{m}^{2} \cdot \mathrm{s}^{-3}\right]$} \\
\hline$\lambda_{2}$ & Secondary dendrite arm spacing & {$[\mathrm{m}]$} \\
\hline$\mu$ & Dynamic viscosity & {$\left[\mathrm{Pa} . \mathrm{s}^{-1}\right]$} \\
\hline$\mu_{t}$ & Turbulent dynamic viscosity & {$\left[\mathrm{Pa}_{.} \mathrm{s}^{-1}\right]$} \\
\hline$\rho$ & Density & {$\left[\mathrm{kg} \cdot \mathrm{m}^{-3}\right]$} \\
\hline$\sigma$ & Surface tension & {$\left[\mathrm{N} . \mathrm{m}^{-1}\right]$} \\
\hline$\sigma_{S T}$ & Stefan Boltzmann constant & {$\left[\mathrm{W} \cdot \mathrm{m}^{-2} \cdot \mathrm{K}^{-4}\right]$} \\
\hline Cp & Specific heat & {$\left[\mathrm{J} \cdot \mathrm{K}^{-1} \cdot \mathrm{kg}^{-1}\right]$} \\
\hline $\mathbf{f}_{\sigma}$ & Volumetric surface tension force & {$\left[\mathrm{N} . \mathrm{m}^{-3}\right]$} \\
\hline h & Total enthalpy & {$\left[\mathrm{J} . \mathrm{m}^{-3}\right]$} \\
\hline $\boldsymbol{k}$ & Turbulent kinetic energy & {$\left[\mathrm{m}^{2} \cdot \mathrm{s}^{-2}\right]$} \\
\hline
\end{tabular}




\begin{tabular}{lll}
\hline $\boldsymbol{k}_{\boldsymbol{c}}$ & Curvature & {$\left[\mathrm{m}^{-1}\right]$} \\
\hline $\mathbf{k}$ & Thermal conductivity & {$\left[\mathrm{W} \cdot \mathrm{m}^{-1} \cdot \mathrm{K}^{-1}\right]$} \\
\hline $\mathbf{k}_{\mathbf{t}}$ & Turbulent thermal conductivity & {$\left[\mathrm{W} \cdot \mathrm{m}^{-1} \cdot \mathrm{K}^{-1}\right]$} \\
\hline $\mathbf{L}$ & Latent heat of melting & {$\left[\mathrm{J} \cdot \mathrm{kg}^{-1}\right]$} \\
\hline $\mathbf{P}_{\text {arc }}$ & Power delivered by the arc to the electrode & \\
\hline $\mathbf{P}_{\text {rad }}$ & Power radiated from the electrode lateral wall & \\
$\mathbf{P}$ & Pressure & {$[\mathrm{K}]$} \\
\hline $\mathbf{T}$ & Temperature & {$[\mathrm{K}]$} \\
\hline $\mathbf{T}_{\text {sol }}$ & Solidus temperature & {$[\mathrm{K}]$} \\
\hline $\mathbf{T}_{\mathbf{l i q}}$ & Liquidus temperature & {$\left[\mathrm{m} \cdot \mathrm{s}^{-1}\right]$} \\
\hline $\mathbf{U}$ & Velocity vector & \\
\hline $\mathbf{m}$ & Metal & \\
\hline $\mathbf{V O F}$ & Volume Of Fluid & \\
\hline $\mathbf{C S F}$ & Continuum Surface Force & \\
\hline $\mathbf{C F L}$ & Courant-Friedrich-Lewy & \\
\hline $\mathbf{M U L E S}$ & Multidimensional universal & limiter \\
& explicit solution & with \\
\hline
\end{tabular}

\section{Introduction}

Vacuum arc remelting (VAR) is a secondary remelting process used to improve cleanliness as well as chemical and mechanical homogeneity of metal ingots. VAR was the first remelting process to be used commercially for superalloy processing. It is also typically the final stage in the melting cycle of reactive metals such as titanium and zirconium alloys. ${ }^{[1]}$

The process consists of melting a consumable electrode under vacuum (see Fig. 1). The heat source is a DC electric arc of low voltage and high current. The arc is created between the electrode (cathode) and the base plate of a water-cooled copper crucible at the beginning of the melt, then between the electrode and the secondary ingot (anode) forming in the crucible. The melting of the tip of the electrode generates a liquid metal film under the electrode, from which metal drops are produced that fall under the action of gravity into the crucible and progressively solidify to form the secondary ingot. At any instant, the ingot is composed of three zones: the fully solidified metal, the liquid pool fed by metal drops and an intermediate mushy zone. 


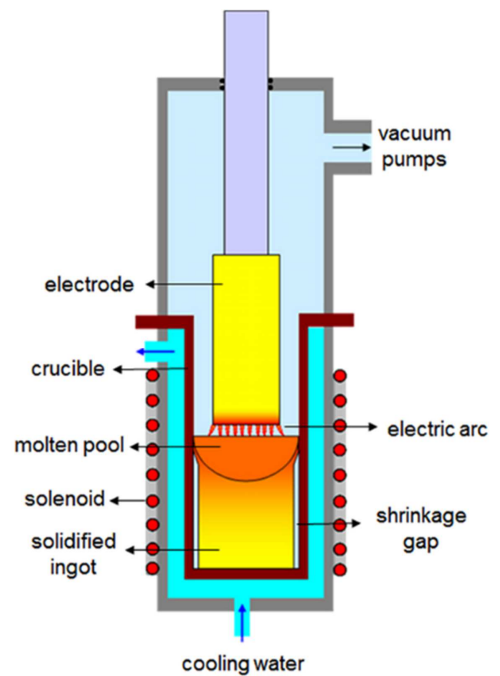

Figure 1: Schematic representation of the vacuum arc remelting process.

The quality of the produced ingots strongly depends on the operating conditions of remelting. Among them, the melt rate and the interelectrode gap play a key role, since they have significant effects on heat transfer conditions at the free surface of the liquid pool, which have important implications on the ingot structure and chemical homogeneity ${ }^{[2]}$.

The VAR process has been investigated previously with both experimental and numerical approaches. On the experimental side, some studies were devoted to establish various correlations between the operating parameters ${ }^{[3,4]}$, whereas some research work focused on the electric arc behavior and metal transfer mechanisms in the interelectrode region, which were observed using high speed video cameras in specifically instrumented VAR furnaces ${ }^{[5,6]}$. Modelling of the VAR process is a difficult task, because the process involves a wide range of coupled complex physical and chemical phenomena, such as fluid flow, heat and mass transfer, solidification (macro and microsegregation), electromagnetic forces... In the literature, most modelling works deal with the development of Computational Fluid Dynamics (CFD) models of the ingot growth and solidification. The majority of authors considers a 2D axisymmetric geometry of the ingot and solves the conservation equations of mass, momentum and energy, accounting for turbulence phenomena and electromagnetic forces in the liquid pool as well as the solidification of the metal. Examples of such models are the SOLAR code ${ }^{[7]}$ and the MeltFlow-VAR code ${ }^{[8]}$. More recently, a multiscale 3D numerical model of VAR was developed by Pericleous et al. ${ }^{[9]}$, which deals also with the ingot behavior. Contrary to the ingot, the consumable electrode has received relatively little attention, with very few modelling works reported, all restricted to thermal phenomena in the electrode. Numerical studies on the formation and dynamics of the liquid film under the electrode are in particular missing up to now. Bertram and Zanner ${ }^{[10]}$ described a transient and one-dimensional model of the heat transfer in the electrode, which was applied to study the effect of the melting current and the gap length on the electrode melting. A similar model, including an explicit account of radiative losses from the lateral walls of the electrode, was presented by Jardy et al. ${ }^{[1]}$. Lately, a step forward was made by El Mir et al. ${ }^{[12]}$ and Jardy et al. ${ }^{[13]}$, who reported an unsteady model of heat transfer in the electrode, considering respectively $2 \mathrm{D}$ and $3 \mathrm{D}$ geometries. Besides the electrode melt rate, these latter models enable to predict, contrary to previous studies, the evolution of the shape of the electrode tip throughout the melt. 
The present work focuses on the interelectrode gap of the VAR process. The aim is to numerically study the formation and deformation of the liquid film under the electrode and the transfer mechanisms of the liquid metal in the interelectrode gap. A further objective is to predict the melt rate of the electrode for a given electric arc power. For this purpose, a 3D model describing the melting of the consumable electrode and the dynamics of the liquid film formed at the electrode tip was developed using the CFD open source software OpenFOAM. The model considers fuid flow under turbulent regime, heat transfer with phase change and the deformation of the free surface of the liquid film. The model is concerned with both large interelectrode gaps, for which the metal transfer results from the formation of molten metal drops from the electrode and their detachment before contacting the ingot, and short interelectrode gaps, for which the metal transfer involves the formation of intermittent molten metal bridges (drip-shorts) between the electrode and the ingot. In section 2, the model is described, including physical and mathematical issues, constitutive equations, boundary conditions and the numerical procedure. In section 3, examples of model results detailing the computed dynamics of the liquid film and thermal behavior of the electrode during the VAR melt of a small-scale electrode and a fully-scale one are presented. Finally, conclusions of the present study are drawn in section 4.

\section{Numerical model}

The formation and dynamics of the liquid film under the consumable electrode during the VAR process is simulated with a multiphase CFD approach. The metal phase change is accounted for using the enthalpy-porosity method ${ }^{[14]}$ and the shape and position of the free surface of the liquid film are calculated using the volume of fluid (VOF) interface capturing method ${ }^{[15]}$.

The developed model is based on the following assumptions.

(1) The heat flux provided by the arc to the electrode is considered to be uniformly distributed at the base of the electrode. The influence on the arc heat flux distribution of the motion of individual cathode spots and of the possible existence of a relatively slow ensemble motion of the arc (see e.g. ${ }^{[16]}{ }^{[17]}$ ) is not examined in this study.

(2) As a first step towards a complete description of the liquid film behavior, magnetohydrodynamic effects produced by the arc current (i.e. electromagnetic forces acting on the liquid metal) are not taken into account.

(3) In a VAR furnace, the liquid metal film is exposed to a low pressure arc plasma. The present model does not deal with the description of this complex latter phase, which is represented here as a neutral gas phase.

(4) All thermophysical properties are considered to be independent of temperature and identical in the solid and liquid phases. The metal density is made temperature dependent only in the buoyancy term in the momentum equation.

(5) As explained later in section II.A, when computing the flow, a specific procedure was introduced to eliminate non-physical spurious velocities generated near the interface in the gas region. This procedure is applied at the end of each time step after calculating the flow in both the liquid and gas regions. It is based on a simple filtering scheme designed to set to zero 
the velocity calculated in all computational cells of the gas phase. Note that this filtering was observed to have negligible influence on the flow calculated in the melt pool.

\section{A. Governing equations}

Fluid flow and behavior of the free surface

The computed behavior of the free surface of the liquid metal film is based on the VOF approach. In order to identify the metal-gas interface, the model solves an advection equation of the volume fraction of the metal $\alpha_{\mathrm{m}}$ (either solid or liquid) present in each computational cell:

$$
\frac{\partial \alpha_{m}}{\partial t}+\nabla \cdot\left(U \alpha_{m}\right)+\nabla \cdot\left(U_{r} \alpha_{m}\left(1-\alpha_{m}\right)\right)=0
$$

$\alpha_{\mathrm{m}}=0$ if no metal is present in the cell, $\alpha_{\mathrm{m}}=1$ for a cell completely filled with metal, and $0<$ $\alpha_{\mathrm{m}}<1$ if the interface is present in the cell. In the VOF formulation implemented in OpenFOAM, the volume fraction transport equation contains an additional convective term (third term in Eq. 1), referred to as "compression term". This term compresses the interface by minimizing the numerical diffusion of the volume fraction while ensuring its boundedness. It can be noticed that this additional compression term acts only at the vicinity of the interface region where $\alpha_{m}\left(1-\alpha_{m}\right) \neq 0$. Therefore, it does not affect the fluid flow outside this region ${ }^{[18]}$. The parameter $\boldsymbol{U}_{\boldsymbol{r}}$ in the compressive term is the relative velocity. Since the VOF method considers only a single velocity for the liquid and gas phases, the relative velocity cannot be evaluated directly. The evaluation of $\boldsymbol{U}_{\boldsymbol{r}}$ is performed at cell faces using the following approximation:

$$
U_{r, f}=n_{f} \min \left[C_{\gamma} \frac{|\phi|}{\left|S_{f}\right|}, \max \left(\frac{|\phi|}{\left|S_{f}\right|}\right)\right]
$$

where the max operation is carried out over the entire domain. $\boldsymbol{n}_{\boldsymbol{f}}$ is the face centered interface normal vector, $\phi$ is the face volume flux and $S_{f}$ is the cell face area vector. The parameter $\mathrm{C}_{\gamma}$ is a user specified constant, which controls the contribution of the compressive term: the higher this value, the sharper the interface. Recommended values are in the range 2 $\leq \mathrm{C}_{\gamma} \leq 4$. This constant has been set to 4 in all the simulations presented in this paper.

The gas-liquid metal flow is governed by a single set of continuity and Navier-Stokes equations. Turbulent phenomena in the liquid phase are modeled through the realizable $k-\varepsilon$ model (the well-known equations of this model may be found in ${ }^{[19]}$ ). This model was selected, since it provides better predictions of flows including streamline curvature and recirculation.

- Continuity equation

$$
\frac{\partial \rho}{\partial t}+\nabla \cdot(\rho U)=0
$$

- Navier-Stokes equation 


$$
\frac{\partial \rho \boldsymbol{U}}{\partial t}+\boldsymbol{\nabla} \cdot(\rho \boldsymbol{U} \boldsymbol{U})=-\boldsymbol{\nabla} p+\boldsymbol{\nabla} \cdot\left(\left(\mu+\mu_{t}\right) \boldsymbol{\nabla} \boldsymbol{U}\right)+\boldsymbol{f}_{\boldsymbol{\sigma}}+\rho_{r e f}\left(1-\beta_{m}\left(T-T_{\text {liq }}\right)\right) \boldsymbol{g}-\frac{\mu_{m}}{K} \boldsymbol{U}
$$

The thermophysical properties are calculated as volume fraction weighted averages of the properties of the phases present in the computational cell:

$$
\xi=\alpha_{m} \xi_{m}+\left(1-\alpha_{m}\right) \xi_{g a s}
$$

The turbulent viscosity is computed as a function of the turbulent kinetic energy $\mathrm{k}$ and its dissipation rate $\varepsilon$ and is expressed as:

$$
\mu_{\mathrm{t}}=\rho_{m} C_{\mu} \frac{k^{2}}{\epsilon}
$$

where $C_{\mu}$ is a coefficient (whose expression can be found in [19]) computed as a function of the main strain and rotation rates and the turbulence fields ( $\mathrm{k}$ and $\varepsilon$ ).

Surface tension effects are taken into account through a continuous equivalent volumetric force $f_{\sigma}$ (Continuum Surface Force model) as proposed by Brackbill et al. ${ }^{[20]}$. This force, acting only in the vicinity of the interface and directly linked to the interface curvature $k_{c}$, is defined as:

$$
\boldsymbol{f}_{\boldsymbol{\sigma}}=\sigma \frac{2 \rho}{\rho_{m}+\rho_{\text {gas }}} k_{c} \boldsymbol{\nabla} \alpha_{m}
$$

A problem encountered in this formulation is the presence of numerical parasitic velocity vortices known as "spurious currents" ${ }^{[21]}$. These "spurious velocities" appear in the gas phase near the interface despite the absence of any external forces and can be significant when the capillary effects are predominant. These high velocities force to use very small time steps to maintain the stability of the simulation (CFL criterion), which increases the computational time. In addition, their magnitude does not decrease with neither mesh refinement nor smaller computational time steps ${ }^{[22]}$. In the current study, a filtration method consisting in setting to zero the velocities of the gaseous phase was implemented to eliminate those spurious velocities. This method was not restricted to the interface region, but it was applied to all computational cells of the gas region.

The investigation and modelling of the solid to liquid (melting) process has received much less attention in the literature than that of the liquid to solid (solidification) process. In particular, it remains unclear whether the melting process involves the existence of a mushy region similarly to what it is observed during solidification. To the best of the authors knowledge, existing attempts to model melting (e.g. [34,35]) are all based on the assumption of the existence of a mushy region and treats this region using the classical enthalpy-porosity technique originally developed to deal with solidification. A similar approach is used in the present study, considering a dendritic morphology of the mushy region. It involves the implementation of the last source term on the right hand side of Eq. 3, which is derived from the Darcy law. The mushy zone is treated as a porous medium, whose permeability is calculated using the well-known Kozeny-Carman model, which was extended in the present work to deal with a three phase system (solid-liquid-gas). 


$$
K=\frac{\lambda_{2}^{2}(1-\gamma)^{3}}{180 \gamma^{2}}
$$

In this equation, $\lambda_{2}$ denotes an order of magnitude of the secondary dendrite arm spacing. $\gamma$ is the solid volume fraction in the cell which may be expressed as a function of the metal volume fraction and the liquid volume fraction $\mathrm{g}_{1}: \gamma=\alpha_{\mathrm{m}}\left(1-\mathrm{g}_{1}\right)$. In practice, the effect of this term is as follows. In the fully liquid cells $(\gamma=0)$, the source term is zero and the "classical" Navier-Stokes equation is solved. In the cells where a phase change occurs, the source term dominates over the transient, convective and diffusive terms, thereby forcing to imitate the Kozeny-Carman model ${ }^{[14]}$. In the fully solid cells $(\gamma=1)$, the source term swamps out all other terms in the momentum equation, which forces velocities to zero ${ }^{[23]}$. Strictly speaking, the velocity appearing in the last source term in Eq. 3 should be the relative velocity between the liquid and the solid. Since the solid phase is kept at rest in our simulations, this velocity reduces here to the fluid velocity.

\section{Heat transfer with phase change}

The enthalpy-porosity method is based on the enthalpy formulation of the energy conservation equation:

$$
\frac{\partial h}{\partial t}+\boldsymbol{\nabla} \cdot(h \boldsymbol{U})=\boldsymbol{\nabla} \cdot\left(\left(k+\alpha_{m} C p_{m} \mu_{t}\right) \boldsymbol{\nabla} T\right)
$$

The enthalpy may be computed as the sum of sensible enthalpy and latent heat absorbed when the metal changes from solid to liquid:

$$
h=\int_{T_{r e f}}^{T} \rho C_{p} d T+\rho_{m} \alpha_{m} g_{l} L
$$

The energy conservation may thus be expressed as follows:

223

$\frac{\partial\left(\rho C_{p} T\right)}{\partial t}+\boldsymbol{\nabla} \cdot\left(\rho C_{p} T \boldsymbol{U}\right)=\boldsymbol{\nabla} \cdot\left(\left(k+\alpha_{m} C p_{m} \mu_{t}\right) \boldsymbol{\nabla} T\right)-\rho_{m} L\left(\frac{\partial\left(\alpha_{m} g_{l}\right)}{\partial t}+\boldsymbol{\nabla} \cdot\left(\alpha_{m} g_{l} \boldsymbol{U}\right)\right)+P_{a r c}-P_{r a d}$

224 The second term on the right hand side of Eq. 10 accounts for the evolution of the latent

225 heat during phase change. The liquid-solid interface is not tracked explicitly. Instead, the

226 melting zone is treated as a porous zone as described previously, in which the liquid fraction

227 lies between 0 and 1 . The liquid fraction is a function of temperature and can be, for example,

228 calculated as follows:

$$
\begin{cases}g_{l}=0 & \text { if } T<T_{\text {sol }} \\ g_{l}=1 & \text { if } T>T_{\text {liq }} \\ g_{l}=\frac{T-T_{\text {sol }}}{T_{\text {liq }}-T_{\text {sol }}} & \text { if } T_{\text {sol }}<T<T_{\text {liq }}\end{cases}
$$
arc to the metal. In fact, this power corresponds to a boundary condition of the problem, 
which is treated here as a volumetric source term applied only in the cells crossed by the metal/gas interface (defined as the cells where $\alpha_{m}=0.5$ ). The total power delivered by the arc to the electrode $\mathrm{P}_{\text {tot }}$ is assumed to be uniformly distributed at the electrode base, which leads to the following expression of $\mathrm{P}_{\mathrm{arc}}$ :

$$
P_{a r c, i}=\frac{P_{t o t}}{\sum S_{i}} \frac{S_{i}}{V_{c i}}
$$

where $\mathrm{V}_{\mathrm{ci}}$ is the volume of the cell $\mathrm{i}$ (crossed by the interface), $\mathrm{S}_{\mathrm{i}}$ is the area of the portion of the interface contained in cell $\mathrm{i}$ and $\sum \mathrm{S}_{\mathrm{i}}$ is the total area of the interface. The interfacial area is approximated by the following expression: $S_{i}=2 \alpha_{m}\left|\nabla \alpha_{m}\right| V_{c i}$.

The last term on the right hand side of Eq. 10 represents thermal losses by radiation at the electrode lateral wall towards the crucible wall. The radiative heat fluxes at the electrode base can be neglected, given the small difference between the electrode and ingot diameters and the similarity of the metal temperatures at the electrode base and on the ingot top. Our evaluation of the radiative heat fluxes between the electrode and the crucible is based on a simplified approach, considering radiative exchanges between two infinite parallel planes. The energy flux density radiated by a surface element of the electrode lateral wall may thus simply be expressed as:

$$
\phi_{\text {rad }, i}=\sigma_{s t} \epsilon_{e q}\left(T_{i}^{4}-T_{\text {mold }}^{4}\right)
$$

The equivalent emissivity is defined by:

$$
\epsilon_{e q}=\frac{1}{\frac{1}{\epsilon_{\text {electrode }}}+\frac{1}{\epsilon_{\text {mold }}}-1}
$$

Similarly to the treatment of the heat flux provided by the arc to the electrode base, this radiative flux density is converted into an equivalent volumetric source term.

$$
P_{\text {rad }, i}=\phi_{\text {rad }, i} \frac{S_{i}}{V_{c i}}
$$

\section{B. Boundary conditions}

Figure 2 shows a vertical cross-section of the 3D computational domain and illustrates the boundary conditions used for the simulation. The red lines represent the surface of application of the arc power while the purple lines represent the surface associated to radiative losses. In order to get a realistic simulation of the formation of molten metal bridges (i.e. drip-short) between the electrode and the ingot, the domain includes a liquid region under the electrode representing a part of the molten metal pool present at the ingot top.

The main boundary conditions of the model, for each of the dependent variables under consideration (i.e. metal volume fraction, velocity, pressure, turbulent kinetic energy and its dissipation rate, temperature), are as follows: 
- Metal volume fraction: A fixed value $\left(\alpha_{m}=1\right)$ is specified at the top wall, while a zero normal gradient is imposed at all other walls.

- Velocity: A no-slip boundary condition is used at walls.

- Pressure: The pressure is specified at the outlet.

- Turbulent kinetic energy and its dissipation rate: The normal gradients are set to zero at all boundaries.

- Temperature: The walls as well as the outlet are treated as adiabatic, which results in a zero temperature normal gradient condition.

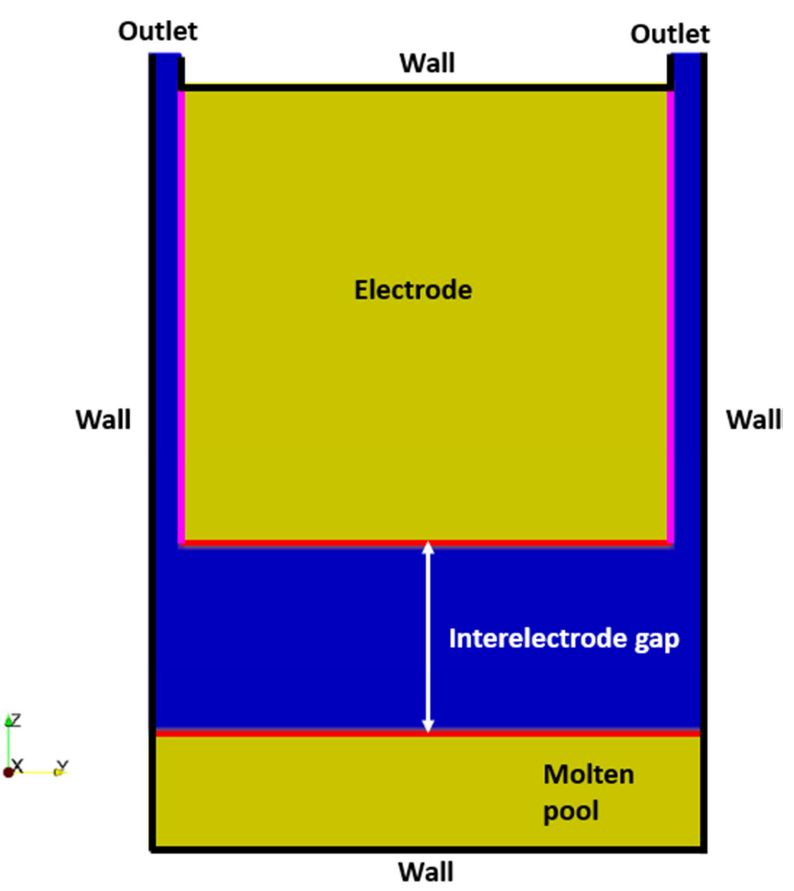

C. Computational details

The pressure-velocity coupling is handled by the PIMPLE algorithm (combination of the PISO ${ }^{[24]}$ and SIMPLE ${ }^{[25]}$ algorithms). The convective terms in the conservation equations are discretized with a second order VanLeer scheme, while the diffusion terms are central differenced. The transport equation of the metal volume fraction is solved using the OpenFOAM solver called InterFoam, which is based on the MULES limited interface compression method. Temporal integration is done using a first order implicit Euler method. The order of magnitude of the time step is $10^{-4} \mathrm{~s}$ and is controlled via a CFL condition (set to 0.5). The simulations are parallelized on 256 processors (DELL C6320, Intel Xeon $2.1 \mathrm{GHz}$ CPU). The computation time of the melt of a $10 \mathrm{~cm}$ high large diameter electrode is about 3 
The numerical model described above was applied to simulate two different melt configurations. The first one is the melt of a small diameter Ti-6Al-4V electrode with a long interelectrode gap performed experimentally by Chapelle et al. ${ }^{[6]}$, while the second one is concerned with the melt of a large diameter maraging steel electrode with a short interelectrode gap performed in a full-scale industrial VAR furnace. The results presented in this section illustrate in particular the different behaviors of the liquid film and transfer mechanisms of the liquid metal according to the gap length. All metal thermophysical properties employed in the simulations are reported in table 1 . The value of the secondary dendrite arm spacing chosen for the maraging steel electrode is based on measurements made with a scanning electron microscope in the frame of the current project. As far as the secondary dendrite arm spacing of the Ti-6Al-4V electrode is concerned, the value of this parameter is unclear. The allotropic transformation of titanium alloys erases evidence of the possible existence of dendrites during the liquid/solid phase change process. Thus, it is not clear whether the phase change involves a dendritic mechanism or another mechanism. In light of this lack of knowledge, it was decided in the present study to assume the occurrence of a dendritic mechanism. The value of the secondary dendrite arm spacing of Ti-6Al-4V was chosen identical to that measured for maraging steel (i.e. $5 \mu \mathrm{m}$ ). The values of the properties of the gas representing the plasma have been chosen arbitrarily and do not correspond to any real gas. Sensitivity analyses have been performed by varying separately each of those values in a limited range and did not reveal any significant influence on the flow calculated in the melt pool.

\section{Parameters}

Density $\rho$

Dynamic viscosity $\mu$

Surface tension $\sigma$

Specific heat $C_{p}$

Emissivity

Thermal conductivity $\lambda$

Dilatation coefficient $\boldsymbol{\beta}$

Liquidus temperature $T_{\text {liq }}$

Solidus temperature $T_{\text {sol }}$

Reference temperature $T_{\text {ref }}$

Latent heat of melting $L$

Secondary dendrite arm spacing $\lambda_{2}$

Ti-6Al-4V
3925
$2.4 \times 10^{-3}$
1.525
831
0.43
33.4
$6.7 \times 10^{-5}$
1625
1595
1625
$2.86 \times 10^{5}$
$5 \times 10^{-6}$

Value

Maraging Steel $^{[27]}$
7933
$5 \times 10^{-3}$
1.93
554
0.5

23

$2.2 \times 10^{-5}$

1450

1413

1450

$2.61 \times 10^{5}$

$5 \times 10^{-6}$

\section{Unit}

$\begin{array}{cc}\text { Gas } & \\ 0,2 & \mathrm{~kg} \cdot \mathrm{m}^{-3} \\ 2.7 \times 10^{-4} & \mathrm{~Pa} \cdot \mathrm{s} \\ - & \mathrm{N} \cdot \mathrm{m}^{-1} \\ 0 & \mathrm{~J} \cdot \mathrm{kg}^{-1} \mathrm{~K}^{-1} \\ - & \\ 9,55.10^{-2} & \mathrm{~W} \cdot \mathrm{m}^{-1} \cdot \mathrm{K}^{-1} \\ 0 & \mathrm{~K}^{-1} \\ - & { }^{\circ} \mathrm{C} \\ - & { }^{\circ} \mathrm{C} \\ - & { }^{\circ} \mathrm{C} \\ - & \mathrm{J} \cdot \mathrm{kg}^{-1} \\ - & \mathrm{m}\end{array}$




\section{A. Small diameter electrode with a long gap}

Fig. 3 shows a vertical cut of the computational domain with the initial metal represented in yellow. The electrode diameter is $160 \mathrm{~mm}$, its height is $150 \mathrm{~mm}$ and the interelectrode gap is $66 \mathrm{~mm}$. The height of the electrode considered here is much smaller than that of the actual electrode, in order to limit the computational time. The total electric arc power is $183.6 \mathrm{~kW}$. The electrode and the metal bath at the ingot top are considered to receive respectively $60 \%$ and $40 \%$ of this power ${ }^{[11]}$. Initially, the electrode is in solid state with a temperature of $25^{\circ} \mathrm{C}$. The liquid bath is at the liquidus temperature of the alloy. The computational grid is a uniform structured mesh consisting of around 3.5 million cells.

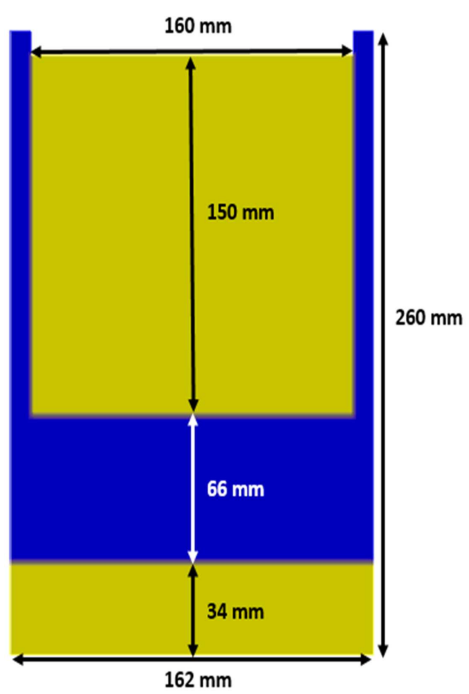

Figure 3: Vertical cross-section of the computational domain used for the simulation of the Ti-6Al-4V electrode.

Liquid film behavior

At the initial state, the electrode is isothermal. The thermal power provided by the electric arc heats the electrode. At this stage, the heat transfer is purely conductive. As soon as the temperature of the tip reaches the solidus temperature, the electrode starts to melt and a distorted liquid film is formed. The film thickness is about $1 \mathrm{~mm}$, which is agreement with the estimates given in the literature ${ }^{[28,29]}$.

Owing to the Rayleigh-Taylor instability which occurs when a heavy fluid is placed above a lighter one in a gravitational field ${ }^{[30]}$, small protuberances appear and are spatially distributed in lattices as shown in Fig. 4, which gives the depth reached by the protuberances in the liquid film. Continuous feeding of the film due to the metal melting eventually destabilizes these structures. The protuberances are subject to horizontal movements. Once they get close to each other, they coalesce, grow and form drops. Such a behavior is qualitatively consistent with the observations made by Limat et al. ${ }^{[31]}$ in a model experiment.

Although the mechanism of formation of the protuberances seems random, the drops appear to detach in specific locations, namely either at the center of the electrode or at its periphery. The dripping sites tend to form a square network with a centered face. This can be clearly seen on the right image of figure 4 , where a drop is about to form in the center due to the 
coalescence of two protuberances, while four protuberances located at the periphery of the electrode will give rise later on to four drops due to the drainage of the liquid film.

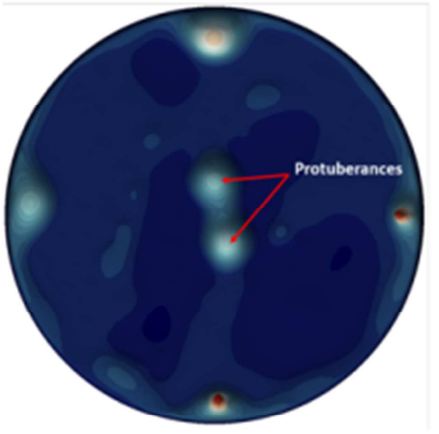

$t_{0}$

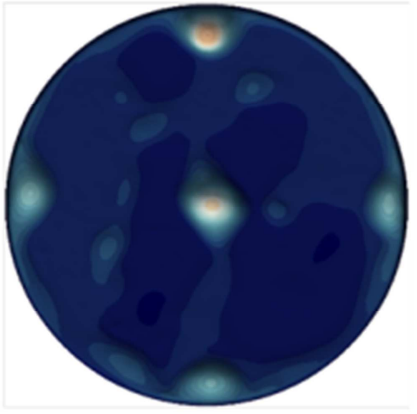

$\mathrm{t}_{0}+70 \mathrm{~ms}$ $\mathrm{t}_{0}+140 \mathrm{~ms}$

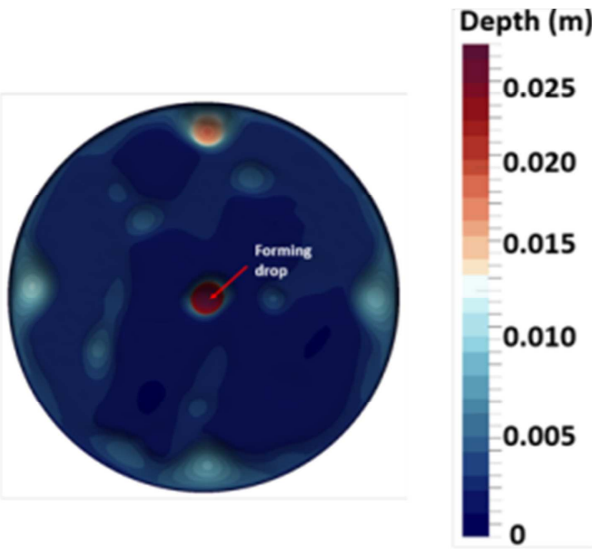

Figure 4: Depth of protuberances formed from the liquid film.

The final growth and the detachment of the central drop observed on the right image of figure 4 are compared in figure 5 with the experimental observations reported by Chapelle et al. ${ }^{[6]}$. On the left image, the protuberance which grows by drainage of the liquid metal has a cylindrical shape. Then it stretches resulting in the formation of a drop. The drop remains attached to the liquid film by a filament which gradually becomes thinner. This latter process eventually triggers the break-up of the filament and subsequent detachment of the drop before touching the molten pool.

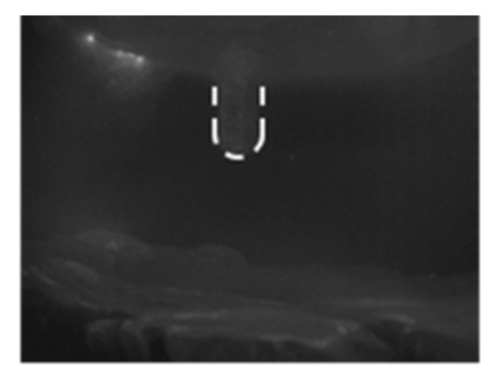

$\mathrm{t}=0 \mathrm{~ms}$

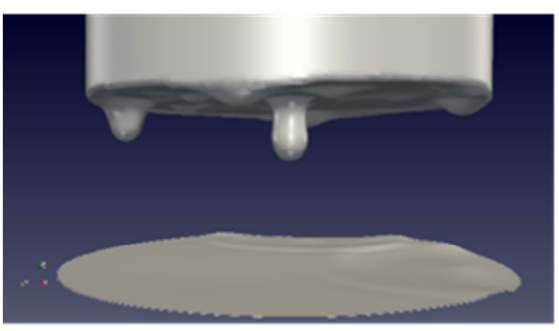

$\mathrm{t}=0 \mathrm{~ms}$

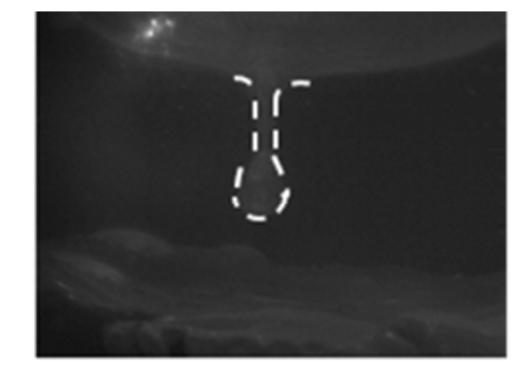

$\mathrm{t}=58.8 \mathrm{~ms}$

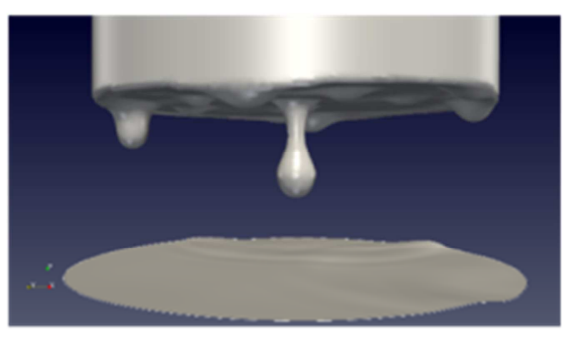

$\mathrm{t}=40 \mathrm{~ms}$

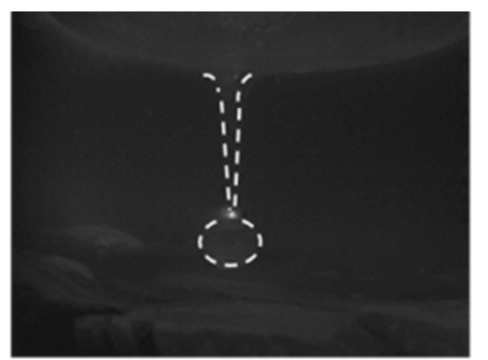

$\mathrm{t}=85.9 \mathrm{~ms}$

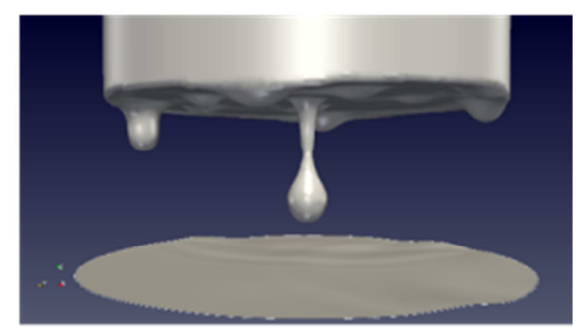

$\mathrm{t}=70 \mathrm{~ms}$

Figure 5: Formation and detachment of a drop observed experimentally [6] (top row) and predicted by the numerical model (bottom row). 
The dimension of the simulated drop is of the same order of magnitude (around $1 \mathrm{~cm}$ ) as that of the actual drop. It is also interesting to note that the characteristic times for each stage are of the same order of magnitude, even if the "numerical" drop takes less time to detach than in reality. Although this comparison can only be qualitative since the simulation does not take into account the electromagnetic effects related to the presence of the arc, the simulated behavior remains close to the experimental visualizations.

\section{Fluid flow inside a protuberance}

As an example of the typical fluid flow present in a protuberance, Fig. 6.a shows a 3D representation of the computed velocity vectors in a protuberance. The fluid flow is fed by the drainage of the liquid film and is governed by buoyancy forces. It is characterized by a large recirculation loop that occupies the whole volume of the protuberance. The velocity magnitude reaches a value of around $8 \mathrm{~cm} \cdot \mathrm{s}^{-1}$ at the central axis of the protuberance. The maximum velocity is reached in the vicinity of the lateral edge of the protuberance and is about $14 \mathrm{~cm}^{-1}{ }^{-1}$. Fig. $6 . \mathrm{b}$ illustrates the turbulence level of the metal flow in the film and in a protuberance. In the protuberance, the turbulence level is moderate, with a maximum value of the ratio of the turbulent to molecular viscosities of about 180 . In the liquid film, the viscosity ratio is much lower, which corresponds to a flow regime remaining laminar.
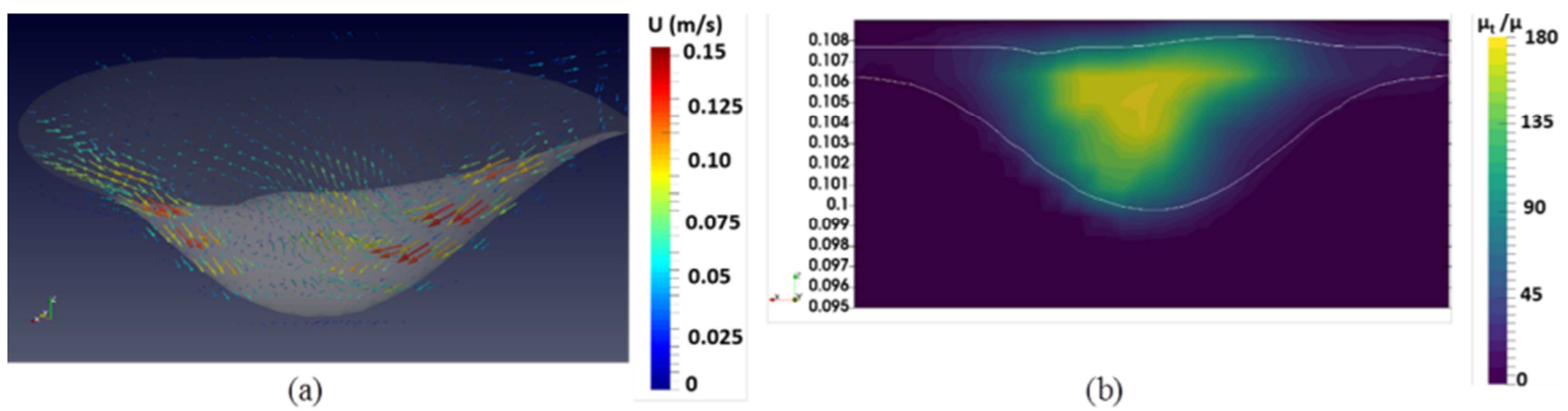

Figure 6: (a) Velocity vectors (3D) inside a protuberance. (b) Turbulent to molecular viscosity ratio in a vertical cross-section of a protuberance.

\section{Heat transfer in the electrode}

The computed temperature field of the electrode at $t=22.2 \mathrm{~s}$ (quasi-stationary regime reached) is presented in Fig. 7.a, while the temperature profile calculated at the same time 
along a vertical line cutting through a protuberance (cf. Fig. 7a) is plotted in Fig. 7.b. Due to the consumption of the electrode, the power supplied by the electric arc affects mainly a small region at the electrode tip, usually referred to as the "heat affected zone". Accordingly, figure 7.b shows a sharp exponential decay in the axial direction of the temperature from the base of the electrode toward the upper part of the electrode. In the present case, the heat affected zone is about $3 \mathrm{~cm}$ high, which is good agreement with the experimental observations of El Mir et al. ${ }^{[12]}$ and the results provided by previous models ${ }^{[10][11,12]}$. As observed in Fig. 7a, the variations in the azimuthal direction of the electrode lateral surface temperature are negligible. Also, the temperature distribution over the surface of the liquid film (excluding the drops) is relatively homogeneous, which is partly related to the uniform arc heat flux distribution considered here.

The superheat of the metal in the liquid film remains small (not exceeding $50{ }^{\circ} \mathrm{C}$ ). On the other hand, a much higher superheat is calculated inside the protuberance, which reaches about $400{ }^{\circ} \mathrm{C}$ at the tip of the protuberance. Such higher superheat may be caused by the recirculating flow of the metal in the protuberance, which contributes to hold the metal inside the protuberance, thus enabling the metal to reach higher temperatures. The predicted value of the superheat of the metal at the free surface of the liquid film is consistent with values reported in the literature for different materials (namely about $100{ }^{\circ} \mathrm{C}$ for IN718 ${ }^{[10]}$ and between $150{ }^{\circ} \mathrm{C}$ and $200{ }^{\circ} \mathrm{C}$ for a zirconium alloy ${ }^{[12]}$ ).

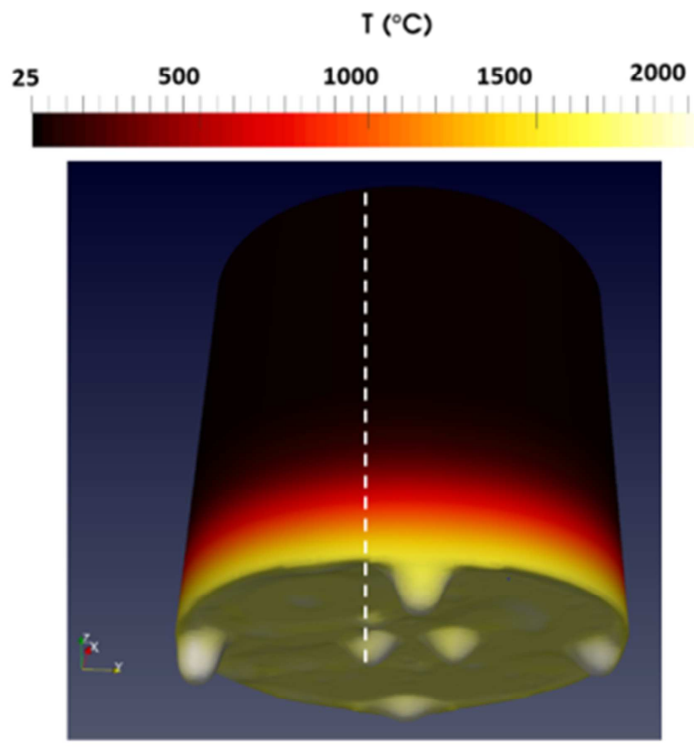

(a)

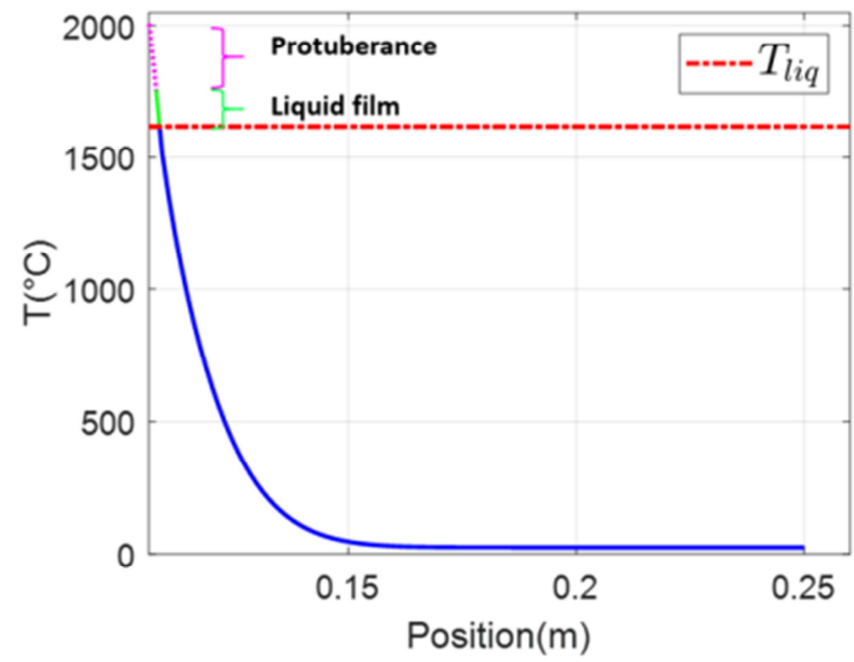

(b)

Figure 7: (a) Temperature field of the outer surfaces of the electrode, (b) Temperature profile along a vertical line cutting through a protuberance. Results obtained during the quasistationary regime at $\mathbf{t}=\mathbf{2 2 . 2} \mathrm{s}$. 


\section{B. Large diameter electrode with a short gap}

Simulation results are presented for an industrial VAR melt of a maraging steel electrode. The electrode considered is $610 \mathrm{~mm}$ in diameter and $150 \mathrm{~mm}$ high (figure 8). Similarly to the previous case; the height of the electrode is significantly reduced compared to that of an actual full-scale electrode, so as to keep the computational time reasonable. The gap length is $10 \mathrm{~mm}$. Again, it is considered that $60 \%$ of the total electric arc power $(300 \mathrm{~kW})$ is transferred to the electrode, while the remaining part (40\%) of this power goes to the metal bath at the ingot top ${ }^{[11]}$. Initially, the electrode is in solid state with a temperature of $25^{\circ} \mathrm{C}$ and the metal bath is at the liquidus temperature. In order to reduce further the computational time, an irregular mesh was used. The mesh is refined inside the gap and in its vicinity and gets progressively coarser moving further away from this area. The number of cells is 2.9 millions.

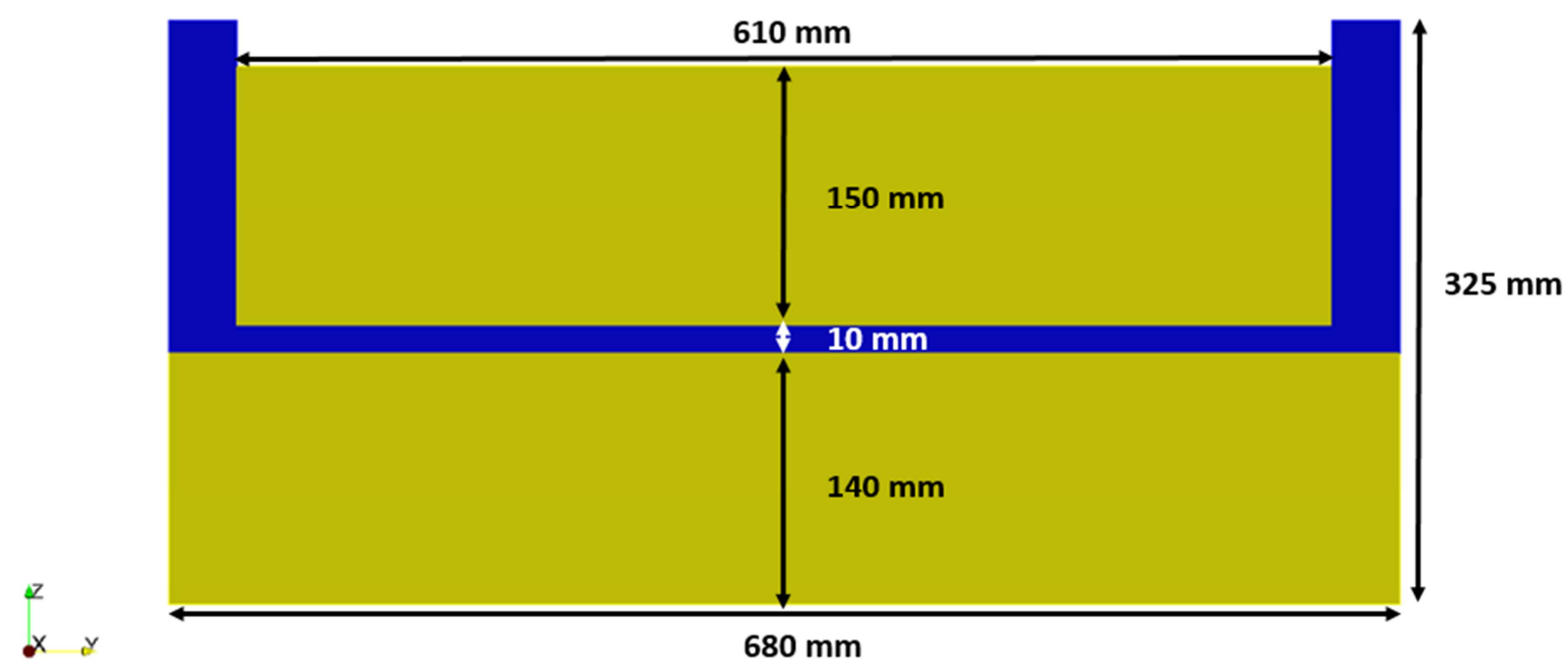

Figure 8: Vertical cross-section of the computational domain used for the simulation of the maraging steel electrode.

\section{$\underline{\text { Liquid film behavior }}$}

Similarly to the observations made above for the melt of a Ti-6Al-4V electrode with a short gap, the destabilization of the liquid film formed at the electrode tip gives rise again to the growth of liquid metal protuberances. However, as illustrated in figure 9a, due to the short gap considered here, the growing protuberances do not evolve into detaching drops but end up forming transient capillary bridges (known as drip-shorts) between the electrode and the metal bath at the ingot top. The mass of the drip-short shown in the figure 9 is $16 \mathrm{~g}$. A part of this amount of metal is eventually transferred to the metal bath as a result of the break-up of the bridge. Such a drip-short based metal transfer mechanism is consistent with the observations made during the actual VAR melt. Indeed, although drip-shorts could not be visualized during the melt, the occurrence of drip-shorts could be monitored through their signatures left on the arc voltage signal. Note that the precise mechanisms of the bridge break-up observed in the 
present simulation results are different from those described in the literature ${ }^{[6]}$, due to the neglect of electromagnetic phenomena in our model.

Fluid flow inside a metal bridgeAs shown in figure 9.b, the fluid flow inside a bridge is characterized by an important drainage of the metal from the liquid film to the metal bath. The velocity magnitude reaches a maximum value of around $22 \mathrm{~cm} \cdot \mathrm{s}^{-1}$ located closed to the central axis of the bridge. The order of magnitude of the ratio of the turbulent to molecular viscosities is about 500, which indicates a significant turbulence level of the metal flow inside the bridge.

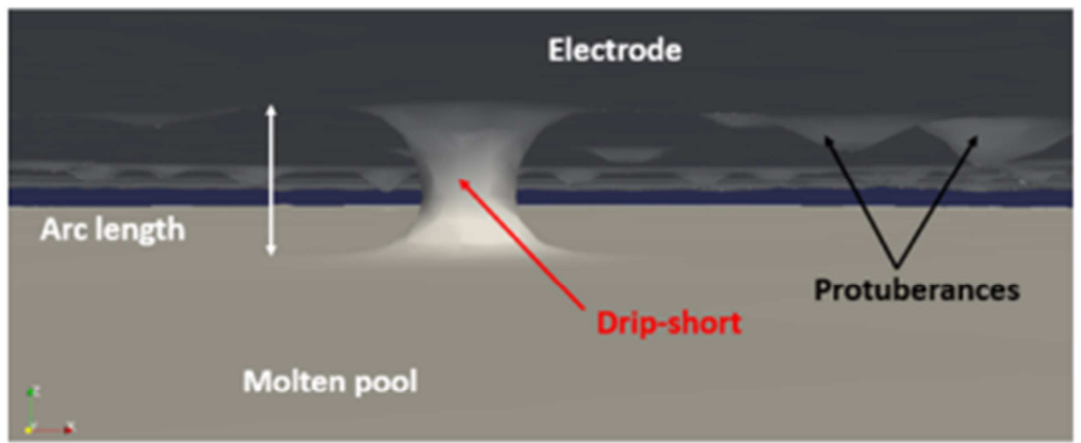

(a)

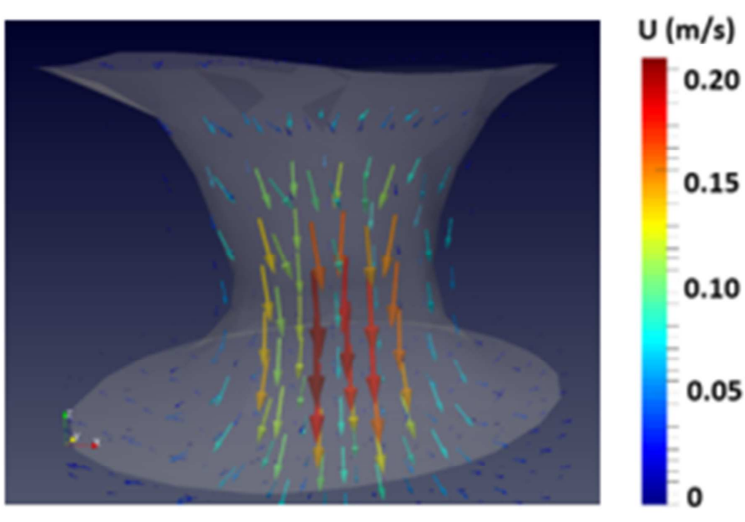

(b)

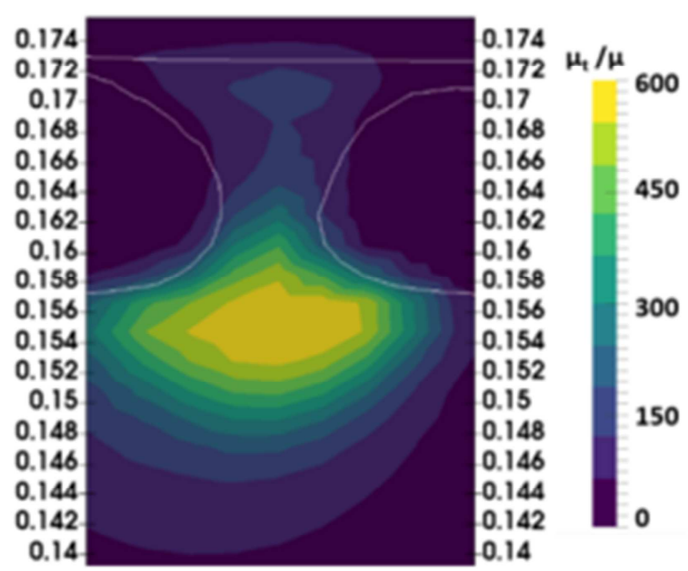

(c)

Figure 9: (a) Example of a calculated capillary bridge (drip-short). (b) Velocity vectors (3D) in the bridge.(c) Turbulent to molecular viscosity ratio in a vertical cross-section of the bridge.

The spatial distribution of the protuberances at the electrode tip at different time instants is shown in figure 10. 


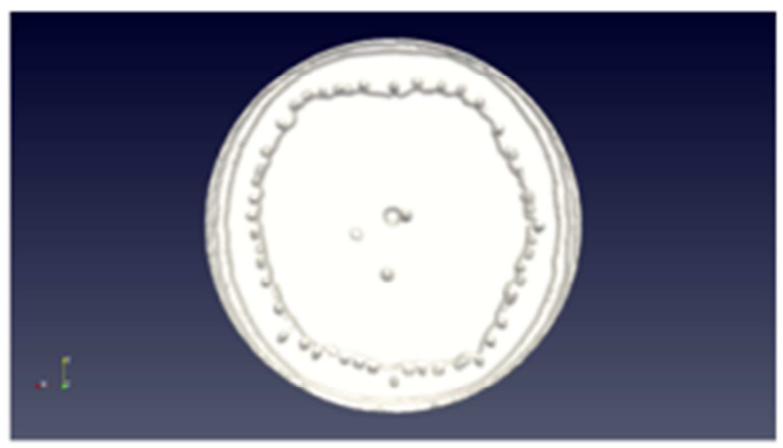

$t_{0}$

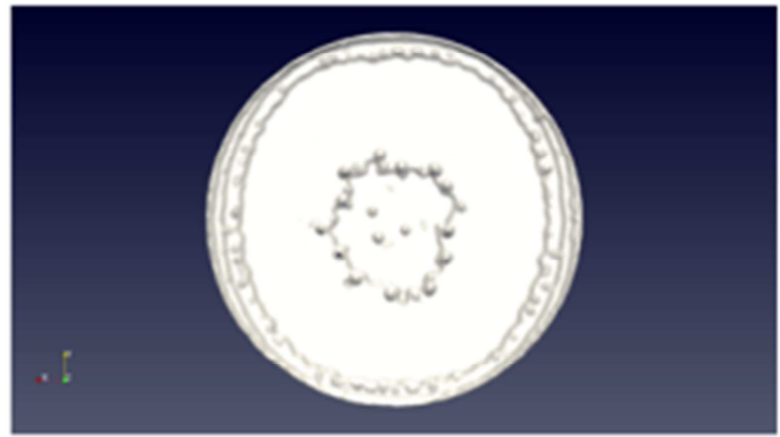

$$
t_{0}+17.75 \mathrm{~s}
$$

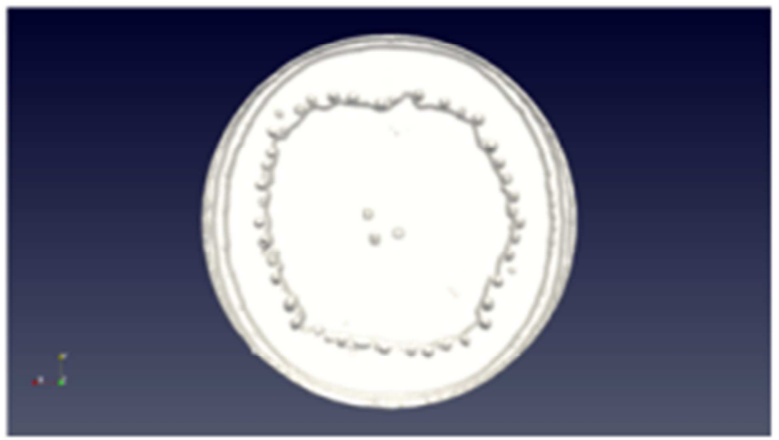

$$
t_{0}+36.2 \mathrm{~s}
$$

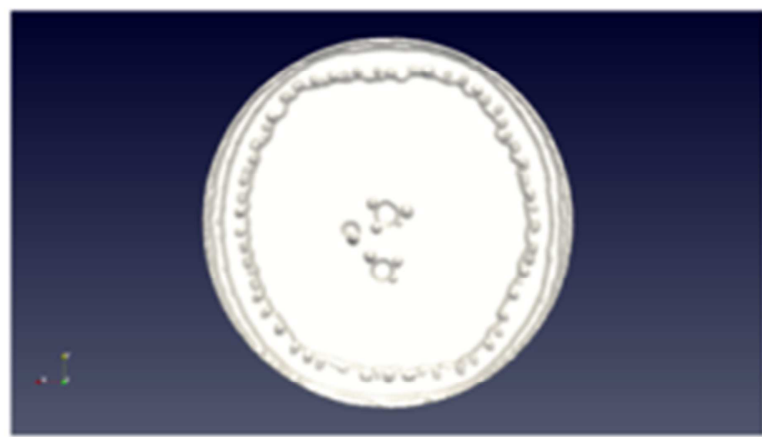

$t_{0}+10.9 s$

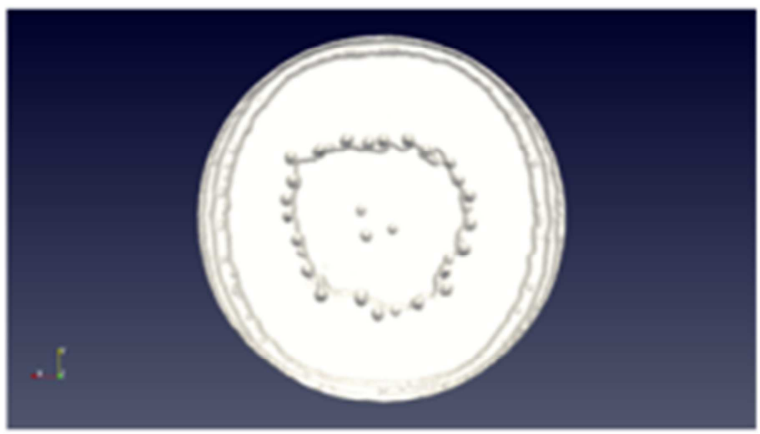

$t_{0}+30.4 s$

Figure 10: Temporal evolution of the protuberance distribution at the tip of the electrode.

Protuberances tend to form near the center of the electrode and migrate to the periphery of the electrode forming approximately concentric circles. This arrangement in concentric circles was previously observed for a $440 \mathrm{~mm}$ superalloy electrode in an experimental study carried 
out by Wadier et al. ${ }^{[32]}$, which consisted in abruptly switching off the arc current and freezing the liquid film with a gas stream. Such a behavior has been attributed by some authors to Lorentz forces ${ }^{[33]}$. According to our simulations, this phenomenon is purely thermohydrodynamic and is likeky to be linked to the concavity of the electrode tip. Due to the cooling resulting from the radiation losses at the lateral surface of the electrode, the melting of the electrode tip is greater at the electrode center than at its periphery, which leads (as will be illustrated below) to a slightly concave shape of the electode tip. Because of gravitational effects, the protuberances appearing near the electrode center tend then to "roll" towards the periphery of the electode, leading to the outward radial motion of the protuberances observed in figure 10. Note that this outward radial motion of the protuberances tends to be periodic, repeating every about $40 \mathrm{~s}$.

\section{$\underline{\text { Heat transfer in the electrode }}$}

Figure 11 illustrates the electrode temperature distribution and the temperature profile along the axis (white dashed line)at $662 \mathrm{~s}$. It can be seen that the electrode tip has a slightly concave shape due to the cooling effect caused by radiation at the electrode lateral surface. Because of the much smaller electrode height to diameter ratio considered here compared to the previous simulation, a quasi-stationary regime is not reached. The heat affected zone is much more important than previously and extends almost all the way to the top of electrode. Moreover, the temperature profile has not a such prononced exponential shape as in the previous simulation (Fig. 7b)..

Similarly to the observations made in figure 7 , the variations of the electrode lateral surface temperature in the azimuthal direction are negligible and the temperature distribution over the electrode tip is relatively homogeneous. The superheat of the metal at the free surface of the liquid film is $60{ }^{\circ} \mathrm{C}$, while that at the tip of a protuberance is much more important and reaches $225^{\circ} \mathrm{C}$.

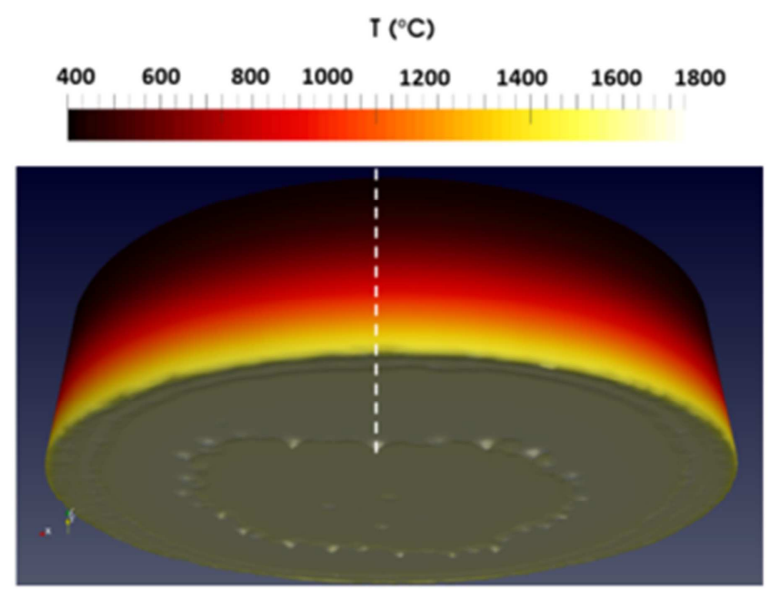

(a)

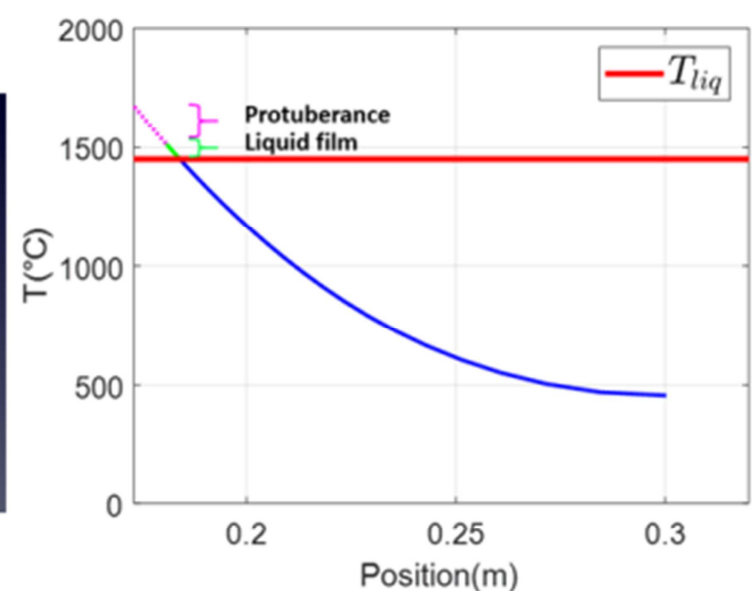

(b)

Figure 11: (a) Temperature field of the outer surfaces of the electrode, (b) Temperature profile along the electrode central axis. Results obtained at $t=662 \mathrm{~s}$ 


\section{Predicted melt rate}

The time evolution of the electrode melt rate calculated (with a sampling rate of $10 \mathrm{~s}$ ) from the evolution of the electrode total mass (including both solid and liquid regions) is plotted in Fig. 12. The electrode begins effectively to melt after a pre-heating stage of about $7 \mathrm{~min}$. The variation of the melt rate is characterized by a sharp increase until reaching a quasi-stationary regime. In the current model, it should be noted that the process starts at full power, contrary to the real process in which the electric current is gradually increased. The average calculated melt rate is $7.2 \mathrm{~kg} \cdot \mathrm{min}^{-1}$ with fluctuations between 6 and $8 \mathrm{~kg} \cdot \mathrm{min}^{-1}$. This value is in good agreement with that monitored during the actual melt which quantitatively validates the present model.

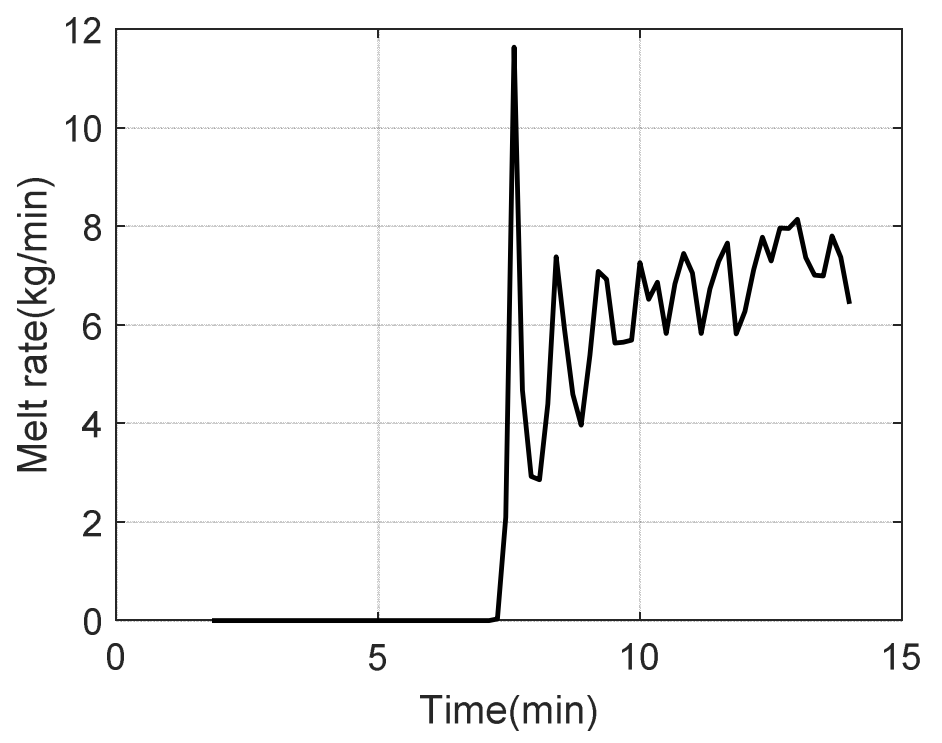

Figure 12: Time evolution of the predicted melt rate of the maraging steel electrode.

\section{Conclusion}

A 3D numerical model was developed in order to simulate the melting of a VAR consumable electrode. This work couples the enthalpy-porosity approach to simulate the melting process and the volume of fluid method to model the deformation of the liquid film formed under the electrode.

The model was applied to simulate the melt of a small diameter Ti-6Al-4V electrode with a long interelectrode gap and that of a large diameter maraging steel electrode with a short interelectrode gap. The model was shown to be able to reproduce two different modes of electrode consumption in accordance with experimental observations. For a long gap, liquid metal protuberances formed at the liquid film surface evolve into drops that eventually detach and fall into the metal bath at the ingot top, while for a short gap (10 $\mathrm{mm}$ in the present work) the metal protuberances evolve until forming intermittent bridges (drip-shorts) between the electrode and the metal bath. Simulation results have shown that the protuberances tend to form circle-shaped patterns appearing near the electrode center and expanding towards the electrode periphery. The metal flow in the liquid film was found to be laminar with a maximum velocity of a few $\mathrm{cm} / \mathrm{s}$. On the other hand, a turbulent flow has been observed in the metal protuberances. 
The metal temperature is relatively homogeneous over the free surface of the liquid film, with a superheat of about $50{ }^{\circ} \mathrm{C}$ and about $60^{\circ} \mathrm{C}$ for the Ti-6Al-4V and maraging steel electrodes, respectively. The metal temperature is larger inside the protuberance than that in the liquid film, which may be caused by the flow structure of the metal in the protuberance. The model enables also to predict the electrode overall melt rate, which compares favorably to the value measured during the melt of the large diameter electrode.

In the future, the present model will be further developed by improving the description of the interactions between the electric arc and the liquid film. Two points need in particular to be addressed. The first one deals with the repartition of the arc power over the electrode tip, considering the actual dynamics of the arc. The second one is the consideration of the influence of electromagnetic forces on the dynamics of the liquid metal.

\section{Acknowledgments}

The authors would like to thank Y. Millet and J. Jourdan from TIMET Savoie, France, who have supported the acquisition of the experimental data shown in figure 5 of the present work.

\section{References}

1 K.-O. Yu: Modeling for Casting and Solidification Processing, CRC Press, 2001.

2 K.O. Yu and J. Domingue: Superalloy 718: Metallurgy and Applications, 1989, pp. 33-48.

3 F.J. Zanner, L.A. Bertram, C. Adasczik, and T. O'Brien: Metallurgical Transactions B, 1984, vol. 15, pp. 117-125.

4 R.L. Williamson, F.J. Zanner, and S.M. Grose: Metallurgical and Materials Transactions B, 1997, vol. 28, pp. 841-853.

5 F.J. Zanner: Metallurgical Transactions B, 1979, vol. 10, pp. 133-142.

6 P. Chapelle, C. Noël, A. Risacher, J. Jourdan, A. Jardy, and Jourdan, Julien: in IOP Conference Series: Materials Science and Engineering, vol. 143, IOP Publishing, 2016, p. 012011.

7 A. Jardy and D. Ablitzer: Xiyou Jinshu Cailiao yu Gongcheng(Rare Metal Materials and Engineering), 2006, vol. 35, pp. 119-122.

8 K.M. Kelkar, S.V. Patankar, A. Mitchell, O. Kanou, N. Fukada, and K. Suzuki: in 11th World Conference on Titanium (Ti-2007), Kyoto, Japan, June, 2007, pp. 3-7.

9 K. Pericleous, G. Djambazov, M. Ward, L. Yuan, and P.D. Lee: Metallurgical and Materials Transactions A, 2013, vol. 44, pp. 5365-5376.

10 L.A. Bertram and F.J. Zanner: Electrode Tip Melting Simulation during Vacuum Arc Remelting of Inconel 718, Sandia National Labs., Albuquerque, NM (USA), 1986.

11 A. Jardy, L. Falk, and D. Ablitzer: Ironmaking \& steelmaking, 1992, vol. 19, pp. 226-232.

12 H.E. Mir, A. Jardy, J.-P. Bellot, P. Chapelle, D. Lasalmonie, and J. Senevat: Journal of Materials Processing Technology, 2010, vol. 210, pp. 564-72.

13 A. Jardy, P. Chapelle, A. Malik, J.-P. Bellot, H. Combeau, and B. Dussoubs: ISIJ international, 2013, vol. 53, pp. 213-220.

14 V.R. Voller and C. Prakash: International Journal of Heat and Mass Transfer, 1987, vol. 30, pp. 1709-1719.

15 C.W. Hirt and B.D. Nichols: Journal of computational physics, 1981, vol. 39, pp. 201-225.

16 R.M. Ward, B. Daniel, and R.J. Siddall: in Proc. Int. Symp. Liq. Met Proc. Cas, 2005.

17 P.-O. Delzant, P. Chapelle, A. Jardy, J. Jourdan, and Y. Millet: Journal of Materials Processing Technology, 2019, vol. 266, pp. 10-18.

18 H.Rusche: PhD thesis, 2002. 
19 T.-H. Shih, W.W. Liou, A. Shabbir, Z. Yang, and J. Zhu: Computers \& Fluids, 1995, vol. 24, pp. 227238.

20 J.U. Brackbill, D.B. Kothe, and C. Zemach: Journal of computational physics, 1992, vol. 100, pp. 335-354.

21 O. Ubbink: PhD thesis, University of London, 1997.

22 D.J. Harvie, M.R. Davidson, and M. Rudman: ANZIAM Journal, 2005, vol. 46, pp. 133-149.

23 A.D. Brent, V.R. Voller, and K.T.J. Reid: Numerical Heat Transfer, Part A Applications, 1988, vol. 13, pp. 297-318.

24 R.I. Issa: Journal of computational physics, 1986, vol. 62, pp. 40-65.

25 S. Patankar: Numerical Heat Transfer and Fluid Flow, CRC press, 1980.

26 K.C. Mills: Recommended Values of Thermophysical Properties for Selected Commercial Alloys, Woodhead Publishing, 2002.

27 V. Descotes: PhD Thesis, Université de Lorraine, 2014.

28 A. Mitchell: ISIJ international, 1992, vol. 32, pp. 557-562.

29 F.J. Zanner, R.L. Williamson, R.P. Harrison, H.D. Flanders, R.D. Thompson, and W.C. Szeto:

Superalloy, 1989, vol. 718, pp. 1989-17.

30 Chandrasekhar: Hydrodynamic and Hydromagnetic Stability, 1961.

31 L. Limat, F. Giorgiutti, M. Fermigier, P. Jenffer, and J.-E. Wesfreid: Revue générale de thermique, 1997, vol. 36, pp. 672-681.

$32 \mathrm{~J} .-$ F. Wadier, Y. Honnorat, and J. Morlet: Influence de La Refusion d'électrodes Consommables Sur La Propreté Inclusionnaire, 1977.

33 A.L. Andreev, N.F. Anoshkin, and G.A. Bochvar: Titanium Alloys. Melting and Casting of Titanium Alloys, Moscow.: Metallurgiya, 1978.

34 Z.S. Saldi: PhD Thesis, Delft University of Technology, 2012.

35 Y. Kim, A. Hossain, and Y. Nakamura: International Journal of Heat and Mass Transfer, 2013, vol. 63, pp. 101-112. 